\title{
Health and Biomedical Informatics: Opportunities and Challenges for a Twenty-First Century Profession and its Education
}

William Hersh

Department of Medical Informatics \& Clinical Epidemiology, Oregon Health \& Science University

Portland, OR, USA

\section{Summary \\ Objectives: Characterize the health and biomedical informatics workforce, its professionalization, and its education. \\ Methods: Literature review and analysis. \\ Results: Athough the value of health information technology is increasingly well-documented, there are sill barriers to its widespread adoption around the world. One of those barriers is a well-defined and competent workforce for developing, evaluating, and implementing systems. There are plenty of opportunities in health and biomedical informatics, yet there also is still much that we do not know about this workforce and its education. Conclusions: Continued efforts must be made to characterize and understand the optimal organization and education of this workforce.}

\section{Keywords}

Informatics as a profession, informatics education, workforce, curriculum

Geissbuhler A, Kulikowski C, editiors. IMIA Yearbook of Medical Informatics 2008. Methods Inf Med 2008; 47 Supp 1:157-64

\section{Introduction}

The benefits of health information technology (HIT) for improving health, health care, public health, and biomedical research are well-known. Several recent systematic reviews have documented the evidence in favor of information technology (IT) interventions [1], clinical decision support [2], and telemedicine [3]. This has led to programs for widespread adoption in places such as England [4] and Canada [5], and calls for increased use in others, such as the United States (US) [6, 7]. There are also opportunities in other areas of biomedical informatics, such as clinical research informatics $[8,9]$ and bioinformatics [10], although there is less research explicitly documenting its value.

Other research, however, demonstrates a low rate of adoption of HIT, especially in the US [11], where most of the evaluative research has been done. As such, the documented benefits are limited to small numbers of institutions. In the HIT intervention systematic review cited above, for example, $25 \%$ of the 257 included studies came from four institutions and only nine of the studies evaluated commercial systems [1]. The barriers to HIT in clinical settings have been well-described, and include mismatch of return on investment between those who pay and those who benefit, challenges to workflow in clini- cal settings, lack of standards and interoperability, and concerns about privacy and confidentiality $[12,13]$. Another barrier, lesser studied and quantified but increasingly recognized, is the lack of characterization of the workforce and its training needed to most effectively implement HIT systems [14-16]. The value of a competent workforce can be demonstrated by a "case report" of one study reporting negative findings with computerized provider order entry (CPOE). In late 2005, a paper was published that reported an increased mortality rate after implementation of CPOE in the pediatric intensive care unit (ICU) of Children's Hospital of Pittsburgh [17]. While the study had some methodological problems, further investigation of their approach demonstrated that their CPOE implementation failed to adhere to known best practices $[18,19]$. In particular, centralization of the pharmacy, installing the system without adequate network and computational resources, and not allowing order entry prior to the patient arriving at the ICU were mistakes that those familiar with known best practices would avoid. Indeed, several other pediatric hospitals looked at their own data and failed to find increased mortality after $\mathrm{CPOE}$ was implemented [20-23].

The methods of this report used a framework to define the problem and organized the results based on the research 
discovered. Such research was obtained through searching MEDLINE and the World Wide Web as well as tracing references in articles and reports about the HIT workforce. A query was also made to the email list of the IMIA Working Group on Education, particularly asking for data from outside the US and Europe.

\section{Statement of the Problem}

As noted by this author previously, data characterizing the HIT workforce is incomplete at best [15]. Yet a variety of studies and communications support the notion that the workforce is important in the successful implementation of HIT. Ash et al. have characterized the important role of organizational behavior, and in particular the "special people" within them, for success of CPOE [24]. Recent news reports in the US quote leaders of HIT projects lamenting the low quantity and lack of training of skilled workers to implement systems that meet their goals [25-27]. Fields that traditionally deal with health and biomedical information, such as librarianship [28, 29] and health information management (HIM) [30], have undergone profound change with this new technology. Public health professionals have also been documented to have deficiencies in their knowledge of IT and how it may improve public health practice [31].

There is a growing recognition that the well-trained HIT professional should have knowledge not only of information technology, but also health care, business and management, and other disciplines. A survey of 91 health care chief information officers (CIOs) found $88 \%$ in agreement that understanding of health care environment is essential to IT practice in health care settings [32]. Sable et al. surveyed health system managers and found a preference for those with clinical experience, understanding of health care, strong communication skills, and ability to work across boundaries within organizations [33].

Another aspect of the problem is that we have little data that characterizes the HIT workforce and, in particular, how it is best trained and deployed for optimal use of the technology. It is traditional in most hospitals and other health care settings to think separately of IT professionals, whom are mostly viewed as technologists, and HIM professionals, who are mostly viewed as maintaining the (usually paper) medical record. This view not only creates artificial distinctions, but also ignores the role that others play in HIT, in particular clinicians who gravitate into such roles.

An additional challenge is that there is no succinct definition of the field of health and biomedical informatics. Furthermore, the field has difficulty agreeing on the adjective in front of the word informatics (i.e., medical vs. biomedical) as well as whether a practitioner should be called an informaticist or informatician (this paper uses the latter). We also do not know where pure IT ends and informatics begins [15]. For example, the individual who installs applications on a desktop computer in a hospital probably does not need formal training in informatics, although the CIO and his or her project leads certainly do. There is also lack of knowledge of the profession by those who advise undergraduates in areas such as biology, in that career opportunities in the field are scarcely mentioned [34]. This has led to calls for health informatics to become a professional discipline [35] and for it to acquire the attributes of a profession, such as a well-defined set of competencies, cer- tification of fitness to practice, shared professional identify, life-long commitment, and a code of ethics [36]. Also a part of the problem is that informatics is not represented in standard occupational classifications, which results in the field not being represented in some types of workforce analyses. In the US, the Standard Occupational Classification (SOC) has codes for Health Diagnosing and Treating Practitioners (29-1000), Medical Records and Health Information Technicians (29-2070), and Computer Specialists (15-1000), but nothing that combines these elements of what informaticians do into a single code [37]. These codes are updated each decade, and it will be imperative for informatics to have such a code in the next revision of the SOC [38]. The same holds for the International Standard Classification of Occupations (ISCO, http://www.ilo.org/ public/english/bureau/stat/isco/), which also has no codes for informatics [39].

\section{What Do We Know About the HIT Workforce?}

There is some data available about those who work in HIT settings, but the data tend to be incomplete. Even further, the focus of any one study tends to fall on one category of the workforce (such as IT or HIM staff) or one application (such as health information exchange). As such, there are no comprehensive assessments of the entire spectrum of those who develop, implement, evaluate, and play other roles with providing support for the use of information in health care, biomedical research, and related areas. There is also little data about those who work in the HIT industry, e.g., for vendors of HIT systems. Nonetheless, there are substantial career opportunities [40]. 
Probably the most comprehensive assessment of the HIT workforce has been carried out in England [41]. An assessment of the English HIT workforce estimated the employment of 25,000 full-time equivalents (FTEs) out of 1.3 million workers in National Health Service (NHS). This equated to the employment of about one IT staff per 52 non-IT workers. The workers were found to be distributed among information and communication technology staff $(37 \%)$, health records staff $(26 \%)$, information management staff (18\%), knowledge management staff $(9 \%)$, senior managers $(7 \%)$, and clinical informatics staff $(3 \%)$. This survey also uncovered other issues raised by professionals in the field, such as retention problems attributed mainly to noncompetitive pay, an anticipation of future skills shortages, and strong support for establishment of a formal informatics profession.

Studies done in the US have focused on one group in the workforce, such as IT or HIM professionals. Gartner Research assessed IT staff in integrated delivery systems of varying size [42]. Among 85 such organizations studied, there was a consistent finding of about one IT staff per 56 non-IT employees, which was similar to the ratio noted above in England. The major roles for IT staff were listed as programmer/analyst $(51 \%)$, support (28\%), telecommunications $(16 \%)$.

Another view of IT staff can be gleaned from the HIMSS Analytics ${ }^{\mathrm{TM}}$ Database (formerly the Dorenfest IDHS+ Database $\left.{ }^{\mathrm{TM}}\right)$. This database contains self-reported data from 33,641 health care entities in the US. Of these entities, 5,054 are hospitals. The data are not complete, and only 2,164 hospitals report IT staff numbers. Even fewer report the distribution of IT staff, and not all who report IT staff also report overall hospital full- time equivalent (FTE) or physician staff numbers. Figure 1 shows the distribution of general job descriptions for the 1,461 hospitals that report such data. Table 1 shows descriptive statistics for total hospital staff FTE, number of beds, and number of hospital physicians per IT FTE. The median value of 68 overall hospital staff per IT staff is relatively consistent with the NHS and Gartner data reported above. The number of physicians employed and/or with staff privileges in US hospitals varies, as does their actual use of the hospital for their patients, so the rightmost column should be interpreted with caution.

Another large-scale study has assessed HIM professionals in the US, finding that the primary work setting for these individuals was hospital inpatient (53.4\%), hospital outpatient (7.8\%), physician office/clinic (7.2\%), and

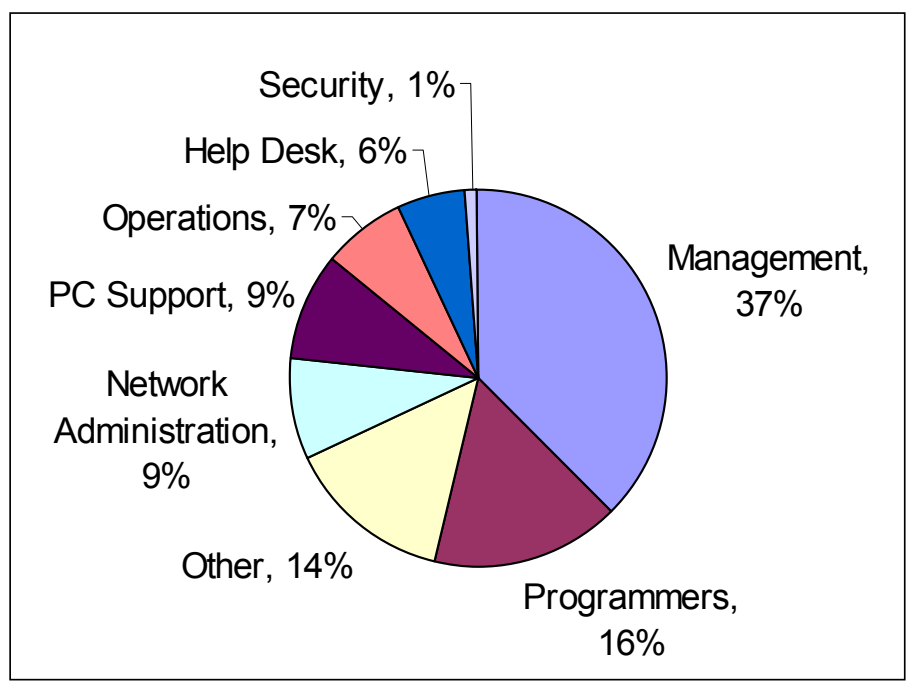

Fig. 1 Distribution of roles of IT staffin US hospitals. [Source: HIMSS Analytics ${ }^{\text {TM }}$ Database (formerly the Dorenfest

IDHS+ Database $\left.\left.{ }^{\mathrm{TM}}\right)\right]$

Table 1 Statistics from hospitals for total staff FTE, number of beds, and number of physicians per IT FTE. [Source: HIMSS Analytics ${ }^{\text {TM }}$ Database (formerly the Dorenfest IDHS + Database ${ }^{\mathrm{TM}}$ )]

\begin{tabular}{|llll|}
\hline Statistic & Total Hospital Staff FTE Per IT FTE & Total Beds Per IT FTE & Total Physicians Per IT FTE \\
\hline $\mathrm{n}$ & 1,979 & 1,979 & 1,444 \\
Mean ( \pm SD) & $100 \pm 164$ & $20 \pm 30$ & $31 \pm 63$ \\
Median & 68 & 13 & 16 \\
\hline
\end{tabular}

consulting firm (4.2\%) [43]. For those involved in EHR implementation, twothirds were on the planning team and half were on implementation team. Study respondents indicated that the largest need for more education was in areas of IT, legal and regulatory issues, reimbursement methodologies, and healthcare information systems. The US Bureau of Labor Statistics has found that job growth for HIM professionals is likely to be high. The most recent projections, for the years 2006-2016, estimate that for those in the SOC of Medical Records and Health Information Technicians, about 170,000 are employed now, which will increase to 200,000 by 2016 , for a growth rate of $17.8 \%$ [44]. There is an estimated need of 76,000 more who must be employed for growth and replacements of those leaving the workforce. Even in a me- 
dium-sized state, the opportunity for growth is not small. A recent assessment of health care workforce needs in the state of Oregon, with a population of about three million, estimated a projected growth of $23.1 \%$ for HIM professionals, with 2,231 employed in 2004 and an estimated 2,747 employed by 2014 [45].

Some workforce studies have focused on the needs with regards to specific HIT applications. For example, a recent analysis looked at the workforce estimated to deploy a Nationwide Health Information Network (NHIN) in the US. [46]. For a five-year implementation time frame, there was an estimated need for 7,600 FTE for installation of EHRs for 400,000 practicing physicians who do not currently have them, 28,600 FTE for the 4,000 hospitals that do not have EHRs, and 420 FTE to implement the infrastructure to connect the network. Table 2 lists the types of personnel needed to implement the NHIN.

Table 2 Types of IT and informatics personnel needed to implement the US Nationwide Health Information Network (NHIN). (Source: [46])

Project Manager
Implementation Coordinator
IT Interface Builder
Change Management Specialist
Desktop Specialist
Database Administrator
Network Engineer
Records Management Specialist
Quality Assurance Specialist
Privacy Officer
Security Officer
Technical Analyst
Trainer
Help Desk Specialist
Chief Medical Information Officer (CMIO)

These data clearly paint a picture of a substantial number of employment opportunities in HIT in the US and England. Likewise, the Head of Canada Infoway project quotes figures from the Conference Board of Canada that estimate creation of 37,000 jobs by full implementation of the Canada Infoway Project [5].

Additional data show that HIT provides well-paying jobs. The 2006 HIMSS Compensation Survey is another selfreported survey [47]. The most recent report of this survey of 1,347 HIMSS members from the US found that the average and median annual salaries were $\$ 102,841$ and $\$ 90,000$ respectively. Salaries were highest in consulting firms, vendor firms, health insurance firms, and larger health care delivery systems. Another assessment of US HIT salaries done in 2007 reported on 417 individuals in a variety of health care delivery organizations (hospital and non-hospital), health plans, and IT companies [48]. Median salaries for "C"-level positions (e.g., CIO, CMIO, $\mathrm{COO}$, etc.) were around $\$ 100,000$ annually. Median salaries for non-"C"level positions varied by hospital size, clinical background, and level of authority, but were above $\$ 100,000$ annually for many.

The American Health Information Management Association (AHIMA) also tracks salary data for HIM professionals [49]. Although the salaries are not as high as for IT staff, with a national average of $\$ 55,676$ annually, there is a large range of salary levels based on job responsibilities, geographical location, and other factors.

This economic outlook is not limited to the US. In an assessment of the first 1024 graduates in medical informatics from the University of Heidelberg and Heilbronn (before March, 2001), it was found that $57 \%$ had an annual salary above $€ 50,000$ [50].

\section{What Do We Know About Informaticians?}

We know even less about those who are called informaticians. These individuals do have a highly diverse array of job backgrounds, titles, and descriptions [51]. Some have backgrounds as health care professionals, while others bring backgrounds in computer science, other life sciences, and many other disciplines. Indeed, on its Web site, the American Medical Informatics Association (AMIA, www.amia.org) notes that its members consist of physicians, nurses, dentists, pharmacists, and other clinicians; HIT professionals; computer and information scientists; biomedical engineers; consultants and industry representatives; medical librarians; and academic researchers and educators.

Hoffman and Ash surveyed potential employers of informatics graduates, asking them to rate most important skills they desired in graduates [52]. They found that the most important skills desired went well beyond technology and included knowledge of clinical information, interpersonal skills, change management, relational databases, and project management.

Likewise, the Knaup et al. survey of University of Heidelberg and Heilbronn graduates found that graduates were employed in many types of organizations, such as [50]: hardware/ software company $(33 \%)$, other company in industry (19\%), academic medical center $(13 \%)$, self-employed (6\%), and non-academic hospital $(5 \%)$. These graduates reported that the most important topics for their work from their studies included database and information systems, software development/engineering, informatics, economics, and information systems in the health care environment. 
Another survey of informatics graduates assessed the biomedical informatics program at the University of Utah [53]. This survey of 209 graduates from the first 35 years of the program found that the most common types of jobs held included operational informatics $(67 \%)$, academic (18\%), medical practice $(16 \%)$, management $(14 \%)$, and research (12\%). These graduates were most likely to be employed in industry (37\%), integrated health care delivery systems $(27 \%)$, and educational institutions (23\%).

How many informaticians do we need? There is no research to quantify this, although a variety of leaders have called for certain numbers of them. In the US, AMIA leaders Drs. Charles Safran and Don Detmer have advocated that there should be at least one physician and one nurse trained in medical informatics in each of the 6,000 hospitals in the US [54]. Likewise, Dr. Charles Friedman, Deputy Director of the Office of the National Coordinator for Health IT has called for 1,000 public health informaticians to be trained based on estimates needed in federal, state, and local public health organizations (Keynote Address, Public Health Information Network, August 26, 2007).

Even if we do not have a quantitative handle on the medical informatics workforce, we can define a framework of informatics practice. Table 4 shows an adaptation of a framework originally developed by Covvey et al. used to define job and role competencies [51]. Their original categories included academic/research and applied/professional practitioners (along with the clinical and biomedical research practitioners, whom we omit from this discussion that is focused on the HIT workforce). An additional category of practice added to the framework, seen increasingly in clinical settings, is the

Table 3 Categories of informatics practice, adapted from [51]

\begin{tabular}{|lll|}
\hline Level of Practice & Type of Work & Example Job Titles \\
\hline Academic & Individual who does research and/or teaching & - Professor \\
& in an academic center & - Scientist or Researcher \\
Applied & Individual who works in an operational & - Chief Information Officer \\
& informatics setting for a majority of his or her & - Chief Medical or Nursing Information Officer \\
& working time & - Project Manager \\
& & - Developer \\
& & - Trainer \\
Liaison & Individual who spends part of his or her & - Chief Medical or Nursing Information Officer \\
& working time as a local expert and interface & - Clinical IT Liaison \\
& with informatics or information technology & \\
professionals & \\
\hline
\end{tabular}

local liaison who provides a bridge between the IT staff and clinical users and who represents the user community.

\section{What Do We Know About Informatics Leaders?}

We know even less about those who are informatics leaders. One survey of member of the Association of Medical Directors of Information Systems (AMDIS) in the US found that of the 82 members who replied, few had formal training in informatics and nearly all of them valued of managerial and clinical over technical skills [55]. Another analysis looked in depth at five Chief Medical Information Officers (CMIOs) [56], finding that the skills they reported to be most important in carrying out their jobs were leadership, communication, and consensus-building. They all expressed a desire to be part of senior physician executive team and did not want to be see as just "techie" doctors.

Another survey of CMIOs was carried out by Gartner and AMDIS [57]. Of the 47 respondents, $70 \%$ were employed in integrated delivery organizations. About 38\% worked as CMIO full-time, another $25 \%$ at $>75 \%$ time, and the remainder for less. The majority of CMIOs reported to CIO and $60 \%$ had no one reporting to them. Three-quarters of them still saw patients part-time and believed it was important for CMIOs to do so. Their top priority was to gain value from investment in clinical information systems. Among the factors they reported as being required for their success were executive-level support and strategic commitment of the organization to IT. The most significant obstacles they reported in their jobs were organizational inertia and physician resistance.

Clearly we need to learn more about informatics professionals and leaders. In many organizations, their role is not well-defined [58]. Of note in the Gartner and AMDIS report is that CMIOs tend not to have reporting relationships to leaders at the highest levels of their organizations, and that they often have no one reporting to them, questioning how much authority they wield in the organizations.

\section{What is the Optimal Education of the HIT Workforce?}

Just as workforce is one barrier to optimal use of HIT, there are also barriers 
to educating that workforce. In addition to the problems of unknown needs cited above, their evolving professional status, and a lack of known best practices for their optimal deployment, we also do not have a clear view of the ideal levels of education and most important competencies to teach such individuals. In recognition of the need to promote awareness of the workforce challenges and increase visibility needed, AMIA and AHIMA held a summit in late 2005 that was followed by a report [14]. The report noted the benefits of HIT would not accrue to the US on a wide scale without a welltrained workforce to implement systems. The report advocated:

- Adopting the Institute of Medicine (IOM) "Quality Chasm" [59] vision

- Creating incentives to adopt "systems" that promote quality through use of HIT

- Establishing industry-wide advocacy for workforce training and development

- Building awareness of the need for workforce development

- Utilizing innovative learning environments to train the workforce

- Developing formal educational programs and promoting their value

- Disseminating tools and best practices for these new professionals to succeed

The IOM, which is a high-profile advocate for improving health care in the US, also sees an important role for informatics, designating it as one of three core competencies required for patient-centered care, along with employing evidence-based practice and applying quality improvement [60]. The competences of individual informatics educational programs are less well developed, but were recently analyzed and determined to be quite diverse [61]. Of course, this will likely change as the workforce and the discipline are better characterized.
The optimal education of the HIT workforce is another gap in our knowledge. Not only do we lack good characterization of the workforce as described above, but we cannot even begin to understand its ideal educational criteria. Despite that, informatics educational programs are growing in size and stature. There are comprehensive Web sites that list and link to such programs internationally (http:// www.hiww.org/) and in the US (http:/ / ww w.amia.org/informatics/ acad\&training/).

These sites demonstrates there are many models for such training. For example, training in the US, UK, and Canada tends to focus at the graduate level (with some notable exceptions), whereas there are many baccalaureate programs in Germany. Likewise, there is a growing use of distance learning in many programs. Many national medical informatics societies address educational issues for their members and students, and the International Medical Informatics Association (IMIA) has a Working Group on Education devoted to worldwide issues (http://imiawged.pbwiki.com/ FrontPage).

Based on the needs in the US advocated by Safran and Detmer quoted above [54], AMIA launched the $10 \times 10$ program, which aims to train 10,000 health care professionals (clinicians and others) in biomedical informatics by the year 2010 [62]. As of early 2008, the program had provided an in-depth introductory course in biomedical informatics to about 400 individuals. Of course, a single course is not enough to educate a full-scope professional in informatics, but about $15 \%$ of those completing the $10 \times 10$ program have gone on for further study (unpublished data, Oregon Health \& Science University).

\section{Conclusions}

These are exciting times for HIT, with its demonstrated value in improving health, health care, public health, and biomedical research and as a pathway to a fulfilling and rewarding career. Clearly there are many job opportunities, with several different studies showing the need for one IT or informatics staff per 50-60 non-informatics staff in a variety of organizations. Such jobs tend to pay well and offer opportunity for career advancement and satisfaction. Indeed, one US newsmagazine recently listed informatics among ten "ahead of the curve" careers [63].

Yet both health care leaders and informatics leaders need more information upon which to base implementation of systems, optimal deployment of the workforce, and the best educational options for the workforce. There is a need for more research to better characterize the workforce of those who develop, implement, and evaluate HIT systems. This will then better inform the development of optimal competencies and curricula for their most effective education and training. Workforce research must go beyond the narrow focus of single groups (e.g., IT staff, HIM professionals, or clinicians) or applications (e.g., EHRs or health information exchanges). Instead, it must focus on the larger picture of all involved in supporting the use of information to improve human health. More effort should also be devoted to establishing occupational coding classifications for informatics jobs and promoting the profession to attract those with passion and competence for it. Additional work must focus on other areas of health and biomedical informatics (such as clinical research informatics, public health informatics, and bioinformatics) as well as other areas of the world (especially outside the US and Europe). 


\section{References}

1. Chaudhry B, Wang J, Wu S, Maglione M, Mojica W, Roth E et al. Systematic review: impact of health information technology on quality, efficiency, and costs of medical care. Ann Intern Med 2006; 144:742-52

2. Garg AX, Adhikari NK, McDonald H, RosasArellano MP, Devereaux PJ, Beyene J, et al. Effects of computerized clinical decision support systems on practitioner performance and patient outcomes: a systematic review. JAMA 2005; 293:1223-38.

3. Hersh WR, Hickam DH, Severance SM, Dana TL, Krages KP, Helfand M. Diagnosis, access, and outcomes: update of a systematic review on telemedicine services. J Telemed Telecare 2006;12(Supp 2):3-31.

4. Chantler C, Clarke T, and Granger R. Information technology in the English National Health Service. JAMA 2006;296:2255-8.

5. Alvarez R. Wouldn't it be Loverly? Putting the Pygmalion Effect to Work in Modernizing Health Care. Healthcare Information Management \& Communications Canada. April, 2007. 21(2): 67. http://www.healthcareimc.com/bcovers/PDFS/ Vol_XXI_2/6_Alvarez.pdf.

6. Brailer DJ. The Decade of Health Information Technology: Delivering Consumer-centric and Information-Rich Health Care. Department of Health \& Human Services: Washington, DC; 2004. http:/ /www.hhs.gov/healthit/documents/ hitframework.pdf.

7. Blumenthal D, Glaser JP. Information technology comes to medicine. N Engl J Med 2007356: 2527-34.

8. Payne PR, Johnson SB, Starren JB, Tilson HH, Dowdy D. Breaking the translational barriers: the value of integrating biomedical informatics and translational research. J Investig Med 2005.53: 192-200.

9. Zerhouni EA. Translational research: moving discovery to practice. Clin Pharmacol Ther 2007;81:126-8.

10. Baxevanis AD, Ouellette BFF. Bioinformatics: A Practical Guide to the Analysis of Genes and Proteins, Third Edition. Hoboken, NJ: WileyInterscience; 2005.

11. Poon EG, Jha AK, Christino M, Honour MM, Fernandopulle R, Middleton B. Assessing the level of healthcare information technology adoption in the United States: a snapshot. BMC Med Inform Decis Mak 2006 6(1). http:// www.biomedcentral. com/1472-6947/6/1.

12. Hersh W. Health care information technology: progress and barriers. JAMA 2004;292: 2273-4.

13. Poon EG, Blumenthal D, Jaggi T, Honour MM, Bates DW, Kaushal R. Overcoming barriers to adopting and implementing computerized physician order entry systems in U.S. hospitals. Health Aff 2004;23:184-90.

14. Anonymous. Building the Work Force for Health Information Transformation. 2006, American Health Information Management Association and American Medical Informatics Association: Chi- cago, IL and Bethesda, MD, http:// www.ahima.org/emerging_issues/ Workforce_web.pdf.

15. Hersh WR. Who are the informaticians? What we know and should know. J Am Med Inform Assoc 2006;13:166-70

16. Perlin JB, Gelinas LS. Electronic Health Records Workgroup Recommendations. 2008, American Health Information Community: Washington, DC, http://www.hhs.gov/healthit/documents/ m20080115/09-ehr_recs_ltr.html.

17. Han YY, Carcillo JA, Venkataraman ST, Clark RS, Watson RS, Nguyen TC, et al. Unexpected increased mortality after implementation of a commercially sold computerized physician order entry system. Pediatrics 2005;116:1506-12.

18. Phibbs CS, Milstein A, Delbanco SD, Bates DW. No proven link between CPOE and mortality. Pediatrics, 2005. http://pediatrics.aappublications. org/cgi/eletters/116/6/1506.

19. Sittig DF, Ash JS, Zhang J, Osheroff JA, Shabot MM. Lessons from "unexpected increased mortality after implementation of a commercially sold computerized physician order entry system". Pediatrics 2006;118:797-801.

20. DelBeccaro MA, Jeffries HE, Eisenberg MA, Harry ED. Computerized provider order entry implementation: no association with increased mortality rates in an intensive care unit. Pediatrics 2006;118:290-5.

21. Longhurst C, Sharek P, Hahn J, Sullivan J, Classen D. Perceived increase in mortality after process and policy changes implemented with computerized physician order entry. Pediatrics 2006;117:1450-1.

22. Jacobs BR, Brilli RJ, Hart KW. Perceived increase in mortality after process and policy changes implemented with computerized physician order entry. Pediatrics 2006;117:1451-2.

23. Rosenbloom ST, Harrell FE Jr, Lehmann CU, Schneider JH, Spooner SA, Johnson KB. Perceived increase in mortality after process and policy changes implemented with computerized physician order entry. Pediatrics 2006;117:1452-5.

24. Ash JS, Stavri PZ, Dykstra R, Fournier L. Implementing computerized physician order entry: the importance of special people. Int J Med Inform 2003;69:235-50

25 . Versel N. Shortage of Health-IT Workers Is Limiting Progress. Digital Healthcare \& Productivity. com. August 28, 2007. http:// www.digitalhcp.com/hitw/newsletters/2007/08/ 28/imia-who/.

26. Rowland C. Hospitals' move to e-files spurs a labor shortage, Boston Globe. Boston, MA. May 14, 2007. http://www.boston.com/business/technology/ a r t i c les / $2007 / 05 / 14 /$ hospitals_move_to_e_files_spurs_a_labor_shortage/

27. McCormack J. Short on support: Too few in health care IT work force. Am Med News July 16, 2007. http:/www.ama-assn.org/amednews/2007/07/16/ bisa0716.htm.

28. Scherrer CS. Reference librarians' perceptions of the issues they face as academic health information professionals. J Med Libr Assoc 2004;92:226-32.

29. Petrinic T, Urquhart C. The education and training needs of health librarians - the generalist versus specialist dilemma. Health Info Libr J
2007;24: 167-76

30. Anonymous. A Vision of the e-HIM Future. American Health Information Management Association: Chicago, IL; 2003. http://library.ahima.org/ xpedio/groups/public/documents/ahima/ bok1_020477.pdf.

31. Leep C, Brown C, Long A. Research Brief: Putting Training on Track. Public Health Informatics Institute: Decatur, GA; 2004. http://www.phii.org/ resources/doc/Training.pdf.

32. Monegain B. Healthcare IT: is it a breed apart?, Healthcare IT News. September, 2004. 4. http:// www.healthcareitnews.com/story.cms?id=1522.

33. Sable JH, Hales JW, Bopp KD. Medical informatics in healthcare organizations: a survey of healthcare information managers. Proceedings of the AMIA 2000 Annual Symposium. 2000. Los Angeles, CA: Hanley \& Belfus. p. 745-8.

34. Eyster KM. Career counseling: 101+ things you can do with a degree in biology. Adv Physiol Educ 2007:31:323-8.

35. Roberts J. Developing health informatics as a recognised professional domain supporting clinical and health management activity. World Hosp Health Serv 2006;42(4):38-40.

36. Joyub R. The Professionalisation of Health Informatics in the United Kingdom. UK Health Informatics Today. Spring, 2004.;42:1-2, 4. http:/ /www.bmis.org/ebmit/2004_42_spring.pdf.

37. Anonymous. Standard Occupational Classification (SOC) User Guide. US Department of Labor - Bureau of Labor Statistics: Washington, DC; 2004. http://www.bls.gov/soc/socguide.htm.

38. Arbuckle DR. Standard Occupational Classification - Revision for 2010; Notice. Federal Register: Washington, DC; 2006. 28536-28538, http:/ /www.bls.gov/soc/soc_may06.pdf.

39. DalPoz MR, et al., Counting health workers: definitions, data, methods and global results, in Background Paper for the World Health Report 2006. World Health Organization: Geneva, Switzerland; 2006. http://www.who.int/hrh/documents/ counting_health_workers.pdf.

40. Hersher BS, Hodges LB. Career Success in Healthcare Information Technology. Chicago, IL: Healthcare Information Management Systems Society; 2004

41. Eardley T. NHS Informatics Workforce Survey. ASSIST: London, England; 2006. http:// w w w. b c s.org/upload/pdf/ finalreport_20061120102537.pdf.

42. Gabler J. 2003 Integrated Delivery System IT Budget and Staffing Study Results. Gartner Corp.: Stamford, CT; 2003.

43. Wing P, et al., Data for Decisions: the HIM Workforce and Workplace - 2002 Member Survey. 2003, American Health Information Management Association: Chicago, IL, http:/library.ahima.org/ xpedio/groups/public/documents/ahima/ bok1_018947.pdf.

44. Dohm A, Shniper L. Occupational employment projections to 2016. Monthly Labor Review 2007; 130(11):87-125. http://www.bls.gov/opub/mlr/ 2007/11/art5full.pdf.

45. Turner B, Nelson J. Oregon Health Care Workforce Needs Assessment 2006. WorkSource Oregon Employment Department: Salem, OR; 2006. http:// www.qualityinfo.org/pubs/single/healthcare.pdf. 
46. Anonymous. Nationwide Health Information Network (NHIN) Workforce Study. Altarum Institute: Ann Arbor, MI; 2007. http://aspe.hhs.gov/sp/reports/2007/NHIN/NHINReport.pdf.

47. Anonymous. 2006 HIMSS Compensation Survey. Healthcare Information Management Systems Society: Chicago, IL; 2007. http:// www.himss.org/surveys/compensation/docs/ CompensationSurvey2006.pdf.

48. Marietti C, Kirby J, Bennet S. What Are Healthcare IT Professionals Worth? A Look at Healthcare IT Salaries. Healthcare Informatics: New York, NY; 2007.

49. Anonymous. 2006 Salary Study. American Health Information Management Association: Chicago, IL; 2006. http://www.ahima.org/membership/ member_profile_data.asp.

50. Knaup P, Frey W, Haux R, Leven FJ. Medical informatics specialists: what are their job profiles? Results of a study on the first 1024 medical informatics graduates of the Universities of Heidelberg and Heilbronn. Methods Inf Med 2003;42: 578-87.

51. Covvey HD, Zitner D, Bernstein R. Pointing the Way: Competencies and Curricula in Health Informatics. University of Waterloo: Waterloo, Ontario, Canada; 2001. http:// www.cs.uwaterloo.ca/health_info/health_docs/
CurriculaMASTERDocumentVersion1Final.zip.

52. Hoffmann S, Ash J. A survey of academic and industry professionals regarding the preferred skillset of graduates of medical informatics programs. MEDINFO 2001 - Proceedings of the Tenth World Congress on Medical Informatics. London, England: IOS Press; 2001. p. 1028-32.

53. Patton GA, Gardner RM, Medical informatics education: the University of Utah experience. J Am Med Inform Assoc 1999;6:457-65.

54. Safran C, Detmer DE. Computerized physician order entry systems and medication errors. J Am Med Inform Assoc 2005;294:179.

55. Conn J. In IT, it pays to think big - survey puts metrics to medical informatics. Modern Physician 7:18-9.

56. Leviss J, Kremsdorf R, Mohaideen MF. The CMIO - a new leader for health systems. J Am Med Inform Assoc 2006;13:573-8.

57. Shaffer V, Lovelock J. Results of the 2006 GartnerAMDIS Survey of CMIOs: Bridging Healthcare's Transforming Waters. Gartner: Stamford, CT; 2007. h t t p : // w w w. gart n e r.co m / DisplayDocument?ref $=\mathrm{g} \_$search\&id $=504632$.

58. Hersher B. The essential skills for the Chief Medical Information Officer. Journal of Healthcare Information Management 2003;17(1):10-1.

59. Anonymous. Crossing the Quality Chasm: A New
Health System for the 21st Century. Washington, DC: National Academy Press; 2001.

60. Greiner AC, Knebel E, editors. Health Professions Education: A Bridge to Quality. National Academy Press: Washington, DC; 2003.

61. Huang QR. Competencies for graduate curricula in health, medical and biomedical informatics: a framework. Health Informatics J 2007;13:89-103.

62. Hersh W, Williamson J. Educating 10,000 informaticians by 2010 : the AMIA $10 \times 10$ program. Int J Med Inform 2007;76:377-82.

63. Nemko M. Ahead-of-the-Curve Careers, US News \& World Report. December 19, 2007. http:// www.usnews.com/articles/business/best-careers/ 2007/12/19/ahead-of-the-curve-careers.html.

\section{Correspondence to:}

William Hersh, MD

Professor and Chair

Department of Medical Informatics \& Clinical Epidemiology

Oregon Health \& Science University

Portland, OR, USA

E-mail: hersh@ohsu.edu

www.billhersh.info 